\title{
Developing a Model Of Pedagogical Content Knowledge For Secondary And Post-Secondary Mathematics Instruction
}
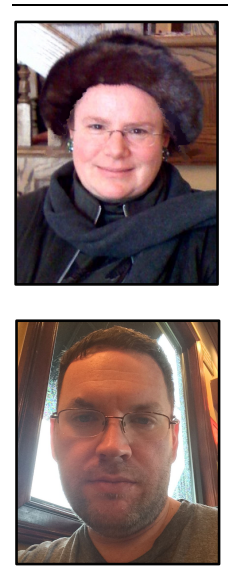

Shandy Hauk

WestEd and

University of

Northern Colorado

Billy Jackson

University of West

Georgia

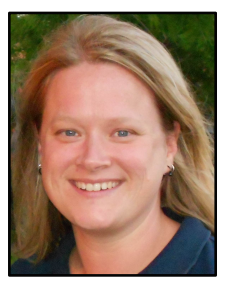

Allison Toney

University of North Carolina

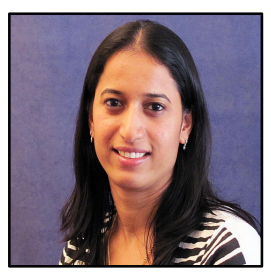

Reshmi Nair University of Northern Colorado
Jenq-Jong Tsay

U. Texas - Pan

American

\begin{abstract}
The accepted framing of mathematics pedagogical content knowledge (PCK) as part of mathematical knowledge for teaching has centered on the question: What mathematical reasoning, insight, understanding, and skills are required for a person to teach elementary mathematics? Many have worked to address this question in K-8 teaching. Yet, there remains a call for examples and theory in the context of teachers with greater mathematical preparation and older students with varied and complex experiences in learning mathematics. In this theory development report we offer background and examples for an extended model of PCK - as the interplay among conceptually-rich mathematical understandings, experience in and of teaching, and multiple culturally-mediated classroom interactions.
\end{abstract}

Keywords: pedagogical content knowledge; discourse; intercultural awareness

Shandy Hauk, an experienced secondary and post-secondary teacher, is a senior researcher at WestEd and affiliate professor in mathematical sciences at the University of Northern Colorado Graduate School. Her PhD is in mathematics with post-doctorate in mathematics education. Centered in culturally and linguistically attentive mathematics and science education, her research and development work includes mentoring doctoral students and post-doctoral researchers. She is principal investigator on several projects that use web-based technologies in support of professional learning among middle school, high school, and college mathematics instructors. She can be contacted at: WestEd STEM Program, 400 Seaport Court - Ste 222, Redwood City, CA 94063. Email: shauk@wested.org

Allison F. Toney is an Associate Professor of Mathematics Education at the University of North Carolina Wilmington. Her research focuses on post-secondary student experiences in learning mathematics and mathematics teacher professional development. A specialist in qualitative research methods, her 


\section{Developing a Model of Pedagogical Content Knowledge for Secondary and Post- \\ Secondary Mathematics Instruction \\ Shandy Hauk, Allison Toney, Billy Jackson, Reshmi Nair and Jenq-Jong Tsay}

secondary research interest is in narrative research techniques, including autoethnography and narrative inquiry. She can be contacted at: Department of Mathematics and Statistics, University of North Carolina Wilmington, 601 S. College Rd., Wilmington, NC 28403. Email: toneyaf@uncw.edu

Dr. Billy Jackson is a mathematician with 6 years of experience in teacher education. He has worked with preservice and in service teachers during his tenure in mathematics education and has contributed to several works on pedagogical content knowledge for teaching mathematics.

Reshmi Nair, previously a high school teacher in India, is a post-doc with the Mathematics Teacher Leadership Center at the University of Northern Colorado. She received her PhD in mathematics from the University of Wyoming. Her mathematics education research interests are in teacher leader development, pedagogical content knowledge of teachers and teacher leaders, distance teaching in mathematics, Mathematical content knowledge for pre-service and in-service teacher development, and intercultural awareness of teacher educators, teachers and students. She can be contacted via email at reshmi.nair@unco.edu

JenqJong Tsay is Associate Professor of Mathematics Education at University of Texas-Pan American. His research specialty areas are teaching, learning, teacher preparation and professional development. $\mathrm{He}$ is project director on several programs for professional development among middle school and high school instructors. He can be contacted at: 1201 W University Drive, Edinburg, TX 78539 MAGC 3.738. Email: jtsay@utpa.edu

$\cos 80$

Since Shulman's (1986) seminal statement on the blends of pedagogical and content knowledge needed for teaching, a rich collection of theories, models, and measures of it has grown in mathematics education (Depaepe, Verschaffel, \& Kelchtermans, 2013). However, work to date has focused on early grades (K-8) teacher development. Current models of knowledge for teaching include little in the way of the classroom sociology and advanced mathematical understandings that are found in high school and post-secondary settings. There is a need for examples and theory in the context of teachers with greater mathematical preparation and older students with varied and complex experiences in learning mathematics (Hauk, Toney, Jackson, Nair, \& Tsay, 2013; Speer \& King, 2009).

The framing of knowledge for teaching mathematics has centered on the question: What mathematical reasoning, insight, understanding, and skills are required for a person to teach mathematics? Many have worked to develop theoretical models and measures to address this question, most notably Ball and colleagues (Ball, Thames, \& Phelps, 2008; Hill, Ball, \& Schilling, 2008). In their work they have proposed three types of subject matter knowledge (SMK) and three types of pedagogical content knowledge (PCK) as non-overlapping categories in the domain of mathematical knowledge for teaching (MKT; Figure 1). With this carefully developed model, and the expectation that the six types of knowledge are distinct, these authors report challenges in identifying and measuring MKT (Hill et al., 2008, pp. 396-398). Despite the challenges, their efforts to create tests to measure (some of) the categories of knowledge have found some success. The practical demands of the current education policy climate in the US call for evidence-based decisions about teacher preparation, induction, and development. Meeting this need requires models and measures of teacher knowledge that are credible 
and transferable across at least some small range of contexts. The MKT model and related instrument development for K-8 teachers have provided a reliable and useful foundation at the lower grades.

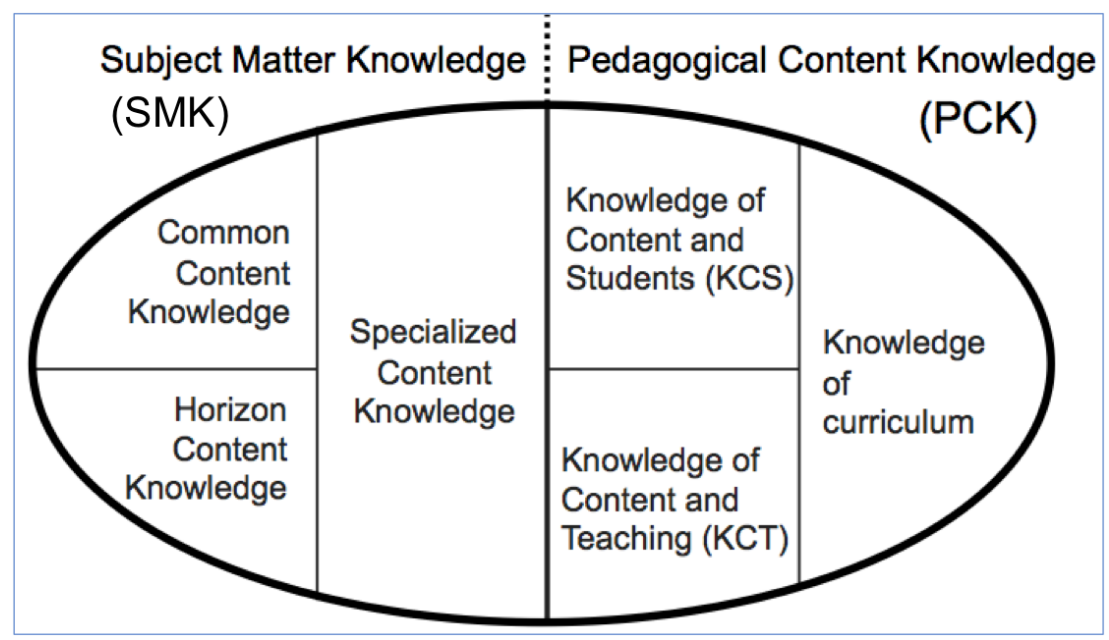

Figure 1. Dimensions of mathematical knowledge for teaching (MKT) from Hill, Ball, and Schilling (2008).

Speer and colleagues (2009, in press) have offered insight into the differing demands of modeling and measuring MKT in secondary and post-secondary contexts. The MKT construct is based on research among K-8 teachers in the United States. Most K-8 teachers have completed few (if any) courses in advanced mathematics whereas secondary teachers typically complete the equivalent of an undergraduate degree in mathematics. For those who teach at the college level, preparation in advanced mathematics is much greater. Many university mathematics teachers are themselves mathematicians, generating new mathematical insights to add to the knowledge base of what constitutes mathematics itself. Using examination of authentic classroom practice, like that behind the development of the MKT model, Speer and colleagues demonstrate that the nature of subject matter knowledge (SMK - the left side of Figure 1) for secondary and post-secondary teachers is different from that of K-8 teachers. They also add to the call for more interview and observation-based investigation into SMK related questions, such as how experiences with pre-publication review of a mathematical peer's work contribute to a university professor's validation and feedback (grading) on student work. They and others continue to explore the nature of SMK in real classrooms, working on how to go about describing and assessing it (e.g., Gitomer, Phelps, Weren, Howell, \& Croft, in press). Emergent from our own teaching and research in secondary and college settings, we extend the exploration of secondary and post-secondary demands and focus on the right half of the picture in Figure 1, the pedagogical content knowledge components, including knowledge of curriculum, of content and students (KCS), and of content and teaching (KCT). Preparatory to clarifying what "pedagogical content knowledge" means, we frame our use of some terms.

\section{Knowledge, Understanding, and Thinking}

In the modern constructivist interpretation of the classical definition, knowledge is the linked collection of mental structures that encode and connect what someone "knows." We say "a knows $p$ " to mean that (1) a accepts $p,(2)$ a has adequate evidence for $p$, and (3) $p$ is true (Hilpinen, 1970). For a constructivist, this definition now begs the questions: What does accept mean? What constitutes evidence (to whom) and who determines its adequacy? And, of course, what does true mean? For our purposes, the answer to each of these questions is: It depends on context. In this report, the context is secondary and post-secondary mathematics teaching and learning in the United States in the early $21^{\text {st }}$ century. While that limits the terrain a bit, we recognize that interpretations of accept, evidence, and truth 


\section{Developing a Model of Pedagogical Content Knowledge for Secondary and Post- \\ Secondary Mathematics Instruction \\ Shandy Hauk, Allison Toney, Billy Jackson, Reshmi Nair and Jenq-Jong Tsay}

we use (and encounter among our teacher colleagues) are constrained by the authoritarian and largely individualistic context of US educational policy and school cultures about mathematics. In these contexts, mathematical knowledge is assumed to be precise and unambiguous, where "any possibility of more than one interpretation for a mathematical expression arises from sloppy use of language rather than any uncertainty of mathematical ideas." (Barwell, 2005, p. 118). Yet, from the constructivist perspective, the cognitive disequilibration needed for learning relies on discursive ambiguity as a resource. It opens the door for meaning- and sense-making activity. In the process of developing knowledge, teachers and learners direct their attention in purposeful ways as interpretations evolve and the complexity of linking grows - sometimes tuning or revising previously connected "knowns" sometimes trimming them, and sometimes de-linking them.

In this setting for knowledge, understanding is a relational dynamic of knowing and purpose, "knowing both what to do and why" (Skemp, 1976, p. 21). For us, understanding is Skemp's "relational understanding." This is distinct from "instrumental understanding," used to describe declarative knowledge, of facts and formulas for instance, unconnected to why to use them. For example, depending on the question, having a correct answer to the question may be evidence of certain kinds of knowledge but may not provide insight into a person's understanding.

By thinking we mean the mental, sometimes embodied, activity of organizing ideas and using knowledge. So, thinking requires and may generate or reconfigure knowledge (e.g., when reasoning), while it may or may not generate understanding.

\section{Current Views of Pedagogical Content Knowledge (PCK)}

Pedagogical content knowledge is more than an overlap of knowledge that is both pedagogically connected and mathematically connected. It is an inextricable blending that is "predicated on coherent and generative understandings of the big mathematical ideas that make up the curriculum." (Silverman \& Thompson, 2008, p. 502). While SMK is about a teacher's understanding of big ideas, PCK is about how that understanding informs thinking and knowledge building about content and students, about content and teaching implementations, and about content of the curriculum. PCK grows when a teacher gets better at the transformation of personal and intimate forms of mathematical knowing into ways of understanding that include how to orchestrate purposeful exploration of that mathematical knowledge among others. Our aim in building a model of PCK is to describe and illustrate an unpacking of these ideas - attending to people's ways of understanding and thinking about and through mathematics in order to teach, while also attending to the reality of cultural heterogeneity in the classroom.

In investigating correlation between K-8 teachers' mathematical knowledge for teaching and quality of instruction, Hill et al. (2008) concluded the existence of powerful relationships among what and how teachers know about mathematics and what occurs during instruction. In addition to the categories in Figure 1, the authors identified (1) beliefs about mathematics, (2) perceptions of mathematics learning and teaching, and (3) decision-making around adoption of teaching material, as significant factors in mediating teachers' instructional performance.

Although an incorporation of the interplay among content, beliefs, culture, and values in pedagogical content knowledge might be relatively new to mathematics education, existing work on science PCK has long included a component of "orientation" (Anderson \& Smith, 1987; Magnusson, Krajcik, \& Borko, 1999) or "disposition" (Park \& Chen, 2012). That is, science PCK models include a melding of knowledge and beliefs about the teaching and learning of the discipline itself, a teacher's personal conceptual map about what is valuable in science as well as in its learning and teaching. A 
common model for teacher orientation towards the discipline spotlights two features: goals and strategies. The variety of orientations that have been identified and named include academic rigor (Lantz \& Kass, 1987), conceptual change (Roth, Anderson \& Smith, 1987), discovery (Karplus \& Thier, 1967), inquiry (Tamir, 1983), and guided inquiry (Magnusson \& Palincsar, 1995). For each of these orientations, Magnusson and colleagues (1999) identified the associated goal(s) for teaching science and core characteristic(s) of instructional strategy. Different goals may be realized with similar strategies (e.g., discovery, inquiry, and conceptual change all involve students exploring and generating ideas, but the goals of each of these orientations towards the discipline differ and the purpose of student activity varies). As currently used in science education, the goals associated with each orientation represent a set of valued ways of seeing the world and of favored tools and artifacts for interacting with the world using science. The characteristics of instruction associated with each orientation include preferred forms of communication, uses of tools and artifacts, and methods for inter-generational transfer (teaching) of these. That is, each named orientation is an instantiation of a culture in a broad sense. And, as currently conceived in the literature, each orientation presumes a particular way of noticing and handling an intercultural difference: between the presumed distinct formal and informal cultures of teacher and student. Teacher orientations are assumed to be close or far from a "formal" or normative academic culture of science while students are viewed as bringing to learning a non-standard or "informal" home culture of science (individually or collectively).

A simultaneous thread in mathematics and science education over the last 30 years has been work that looks at student orientations towards the learning and teaching of the discipline. Steeped in concerns of cultural relevance, responsiveness, and situated cognition, this work has paralleled that of teacher orientation in looking at goals and characteristics of learning and its measurement, but with a focus on students (e.g., Gay, 2010; Greeno, 1998; Solano-Flores \& Nelson-Barber, 2001).

Only recently have mathematics and science education begun to consider the intercultural differences and, to our knowledge, very little work has been done on teacher orientation to the difference - not orientation toward teaching and learning of science or mathematics, but orientation toward the differences between teacher and student orientations about a discipline's teaching and learning. Evidence of both orientation towards the discipline and orientation towards the difference manifests in the secondary and college classroom in myriad ways. Researchers have investigated the vocabulary (e.g., the mathematical register, Wells, 1993), discourse practices (e.g., Moschkovich, 2007; Ryve, 2011), gestures (Alibali et al., 2012), and setting of norms for talking about the discipline (e.g., sociomathematical norms, Yackel, Rasmussen, \& King, 2000). If pedagogical content knowledge is the reshaping and melding of knowledge and beliefs about mathematics and pedagogy into instructional realizations in the classroom, then certainly the aspects of communication just listed are part of PCK. But where in Figure 1 are these dynamics?

Here we report on our efforts to develop an expanded model of pedagogical content knowledge in secondary and post-secondary contexts that considers a key aspect of Shulman's (1986) original framing that is not explicit in existing models in mathematics education. Based on work discussed below, it is called knowledge of discourse. This brings to PCK the discipline-steeped semiotics that is part of advanced mathematics and that was part of Shulman's original description:

The syntactic structure of a discipline is the set of ways in which truth or falsehood, validity or invalidity, are established... Teachers must not only be capable of defining for students the accepted truths in a domain. They must also be able to explain why a particular proposition is deemed warranted, why it is worth

Dialogic Pedagogy: An International Online Journal | http://dpj.pitt.edu DOI: 10.5195/dpj.2014.40 | Vol. 2 (2014) 


\section{Developing a Model of Pedagogical Content Knowledge for Secondary and Post- \\ Secondary Mathematics Instruction \\ Shandy Hauk, Allison Toney, Billy Jackson, Reshmi Nair and Jenq-Jong Tsay}

knowing, and how it relates to other propositions, both within the discipline and without, both in theory and in

practice... This will be important in subsequent pedagogical judgments. (Shulman, 1986, p. 9)

Ultimately, we seek to develop theory, models, guidelines, and measurement tools that allow exploration of questions such as: What is the interplay among advanced mathematical understandings, teaching, and culturally mediated communication in defining and growing pedagogical content knowledge?

A useful model can inform research, policy making, and classroom practice. The purpose of this article is to introduce a model that can be used to help educators, researchers, and teachers better identify, document, and measure PCK. As Ball and colleagues have noted, "to those interested in building theoretical coherence around mathematical knowledge for teaching, the variety of approaches is distressing" (Hill et al., 2007, p. 131). In order to open conversation rooted in a common vocabulary, we use Ball's MKT model as our foundation. The notion of common vocabulary includes the effort to identify key aspects of PCK in order to create learning goals for teacher education and mathematician preparation (e.g., during early teaching experiences in graduate school) and contribute to the theoretical perspectives informing the design and interpretation of measures of the effectiveness of teacher professional learning. In particular, developing relational understandings that link among the components on the right of Figure 1 involves types of knowledge and thinking that are not explicit in the current MKT model. We expand on the existing MKT model of PCK by considering discourse and the role it plays in the mathematics classroom. We also consider the connections among the different components of PCK that we claim are interwoven with each other and not distinct as the existing model treats them.

Our proposed model relies on three existing theories related to human interaction in mathematics teaching and learning: for discourse, for intercultural awareness, and for PCK. We start with brief definitions associated with "discourse," make a foray into some key ideas in intercultural orientation, and then describe the revised model. We conclude with classroom vignettes and brief analyses of them to illustrate the theorized constructs. These illustrations are not definitions. They are offered as anchors for discussion.

\section{Background on Discourse}

\section{Conceptual framework: How do language and culture shape teaching and learning?}

Meaning is situated. Consider how to interpret: "The coffee spilled, get a mop" and "The coffee spilled, get a broom" (Gee, 1999, p. 48). In each case, cultural models (context-based storylines that may or may not be consciously considered) are connected to the word "coffee." The cue of "mop" is likely to trigger a situated meaning for coffee as a liquid while, depending on one's experience and available cultural models, "broom" may be more likely to bring to mind dried beans (perhaps whole, or perhaps ground up). Meaning also is situated in larger conversations of current and historical social experiences and cultural practices. Situated meanings are dynamic in that they are assembled on the spot, based on past and present experience, "customized in, to, and for context, used always against a rich store of cultural knowledge (cultural models) that are themselves 'activated' in, for, and by contexts." (Gee, 1999, p. 63). People use language to express their personal and social identities, some in ways that are rooted in everyday out-of-school interactions and relationships, the "lifeworld" (Habermas, 1984). Others primarily perceive and use language in ways that separate or defer the lifeworld. For instance, language used in school may privilege a future-self defined by "success" where "success" is given by values, norms, and achievements characteristic of powerful institutions in a particular culture (e.g., in the US 
majority culture, by grades or monetary wealth). The differences between the personalized narrative lifeworld and the language and processes of "success" rhetoric give one example of the myriad ways students' and teachers' personal contexts may differ.

In his review of over 100 research publications in mathematics education that reported on "discourse," Ryve (2011) concluded that conceptualizations of discourse have been varied in detail and diverse in scope. What Ryve found was that the myriad conceptions of "discourse" could be understood through the work of Gee (1996), who distinguished between "little d" discourse and "big D" Discourse. "Little d" discourse is about language-in-use. In mathematics teaching and learning, this may include connected stretches of utterances and other agreed-upon ways of communicating mathematics such as symbolic statements or diagrams. Discourse ("big D") is situated "little d" discourse, encompassing verbal and non-verbal aspects, from the subtleties of preferences in local vocabulary and forms of symbolic or diagrammatic representation to the nuances of gesture, tone, hesitation or wait time, facial expression, hygiene, and other aspects that make for authenticity in an interaction (Gee, 1996). In what follows, our use of the term "discourse" is in the "big D" sense.

Like any culture, a classroom culture is a set of values, beliefs, behaviors, and norms in use by a group, in this case the people in the room, that can be reshaped and handed along to others by those people (Hammer, 2009). Though not everyone in the classroom may describe the culture in the same way, members would recognize the set of classroom norms, values, beliefs, and behaviors that are the intention though they may not agree on a single interpretation or perception of that culture. Gee's more encompassing version of discourse addresses Shulman's attention to semiotics:

A Discourse is a socially accepted association among ways of using language, other symbolic expressions, and 'artifacts', of thinking, feeling, believing, valuing, and acting that can be used to identify oneself as a member of a socially meaningful group or 'social network', or to signal (that one is playing) a socially meaningful 'role' (Gee, 1996, p. 131)

That is, Shulman's original statements about pedagogical content knowledge included knowledge for working effectively with the multiplicity of discourses students, teacher, curriculum, and school bring into the classroom. Each discourse includes a cultural context. Discourses may differ from person to person or group to group. The ways that teachers and learners are aware of and respond to multiple cultures is a consequence of their orientation towards cultural difference, their intercultural orientation. We come back to intercultural orientation after unpacking what we mean by discourse a bit more.

It is worth noting here that our goal is to extend an existing model with language that can contribute to the transformation of research and practice. We do not pretend the teacher-centered tradition of the transmission model (teachers broadcast and students receive) will change to a dialogic one with a snap of the fingers. Language can constrain and construct, sometimes simultaneously. This extended model of pedagogical content knowledge offers language and illustration to support conversation about classroom d/Discourses that may support such change. We join an already moving river of ideas. Various streams of research and development on mathematics teacher learning spring from a research-practice synergy that views all people in a classroom as participants in learning. It is the question of the nature of that learning and of the interaction of the people in its support (for teachers and for students) that is foundational (Schoenfeld, 2013).

Starting from the current state means attending to the fact that the "big D" discourse of academic mathematics esteems particular kinds of "little d" discourse. Valued inscriptions are logico-deductive (e.g., 


\section{Developing a Model of Pedagogical Content Knowledge for Secondary and Post- \\ Secondary Mathematics Instruction \\ Shandy Hauk, Allison Toney, Billy Jackson, Reshmi Nair and Jenq-Jong Tsay}

reasoning, proof) and figural (e.g., representations such as tables, graphs, or diagrams of relationships or mappings). Common in advanced mathematical discourse are explanation, justification, and validation (Arcavi et al., 1998; DeFranco, 1996; Weber, 2004). As in other fields, traditional instruction is teacher-led (if not teacher-centered) and instructors ask questions to evaluate what students know and to elicit what students think. A model of classroom interaction common in the US is the basic discourse pattern of initiation - response - follow-up or $1 \cdot R \cdot F$ (Mehan, 1979; Wells, 1993). In secondary and college classrooms, this is most often initiated by teachers, but not exclusively so, and the (implicit) rules for how initiating, responding, and following-up will happen are worked out by the people in the room (Nickerson \& Bowers, 2008). These rules make up one aspect of what Yackel and colleagues have called "sociomathematical norms" (Yackel, Rasmussen, \& King, 2000).

In his ethnographic work, Mehan identified four types of teacher questions (see Table 1). Research suggests that US mathematics instructional practice is mostly evaluative, living largely to the left of Table 1 (Stigler \& Hiebert, 2004; Wood, 1994). The unfortunate aspect here is not the fact that evaluative questions are common but that eliciting questions are not. These more complex spurs for discourse can lead to iterative patterns that cycle through and revisit the frame of reference "in ways that situate it in a larger context of mathematical concepts" and foster "mathematical meaning- making" (Truxaw \& DeFranco, 2008, p. 514). The use of eliciting, process and metaprocess questions, for example as follow-up $(F)$, readily expands discourse into the "reflective toss" realm of comparing and contrasting different ways of thinking (with justification but without judgment), monitoring of a discussion itself, as well as attending to the evolution of the thinking of others and self (van Zee \& Minstrell, 1997).

Table 1. Initiate-Respond-Follow-up $(l \cdot R \cdot F)$ question types and example response types.

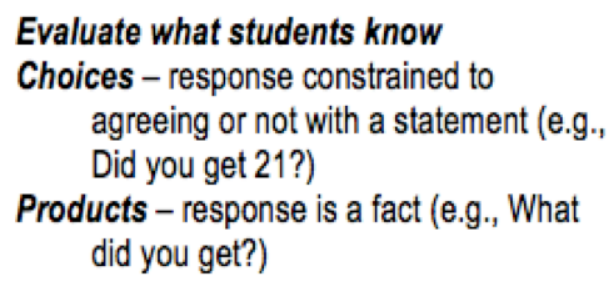

\section{Elicit what students think}

Processes - response is an interpretation or opinion (e.g., Why does 21 make sense here?)

Metaprocesses - response involves reflection on connecting question, context, and response (e.g., What does the 21 represent? How do you know?)

Piaget identified assimilation and accommodation as two interactive processes to explain an individual's adaptation for achieving cognitive equilibration and learning (Driscoll, 1994). Humans are pattern-seekers looking for patterns to recognize for assimilation. If assimilation fails, people may create a new interpretation of ideas, based on available perceptions, for accommodation. From this perspective, teaching is the act of providing productive cognitive conflict so learners may accommodate existing schemes, iteratively, in ways that incorporate rigorous mathematical schemes. That is, concept images are challenged repeatedly by cognitive disequilibration to foster the development of the associated mathematical concept definition (Tall \& Vinner, 1981).

This is in contrast to pseudo-assimilation (e.g., about function; Zandieh, 2000), where one learns to use terms in the mathematics register in a procedural way, without associating the complexities of the associated mathematical meanings. For example, "a quadratic equation has a power of 2 on $x$ and an equal sign in it, so to solve it, use the quadratic formula" is applied with equal vigor to equations of the 
form $x^{2}+b x+c=0$ and $x^{2}+b x+c=x$, but generally only achieves success in the first case. Conversely, nonstandard mathematical terms can support procedural success, at a cost. Consider the common types of pseudo-assimilation discussed by Bair and Mooney (2013). They offered examples of problematic instruction on the distributive property such as "FOIL" and "bam-bamming" two negative signs to a positive in expanding an expression like $-6(4-3 x)$ to $-24+18 x$. Although aiming to reduce what learners may find cognitively overwhelming, these instructional strategies may lead students to unproductive generalizations and counter-productive decisions about mathematical meanings. Similarly, Temple and Doerr (2012) note the importance of developing fluency in the mathematical register. Thought and speech inform each other and struggling through the ambiguities introduced in learning to use technical vocabulary can support mathematical meaning-making (Barwell, 2005). Discourse is central in our effort to bring to PCK theory an explicit attention to the use of language and the dense set of values about mathematical appropriateness, clarity, and precision that are integral to thinking, learning, and communicating, especially in advanced mathematics.

\section{Intercultural Orientation}

As mentioned above, "big D" discourse as part of mathematics pedagogical content knowledge pivots on the idea of intercultural orientation. Our referent framework is the Developmental Model of Intercultural Sensitivity (Bennett \& Bennett, 2004). The developmental continuum of awareness of and orientation towards cultural difference, of "other," runs from a monocultural or ethnocentric "denial" of difference based in the assumption "Everybody is like me" to an intercultural and ethnorelative "adaptation" to difference. The first transition in the path, from denial to the "polarization" orientation, comes with the recognition of the existence of difference, of light and dark in viewing a situation (e.g., Figure 2a).

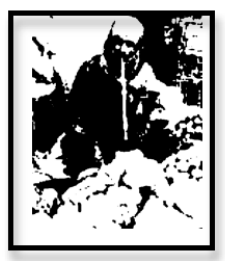

Figure 2a.

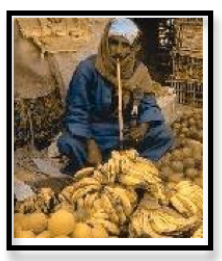

Figure $2 b$.

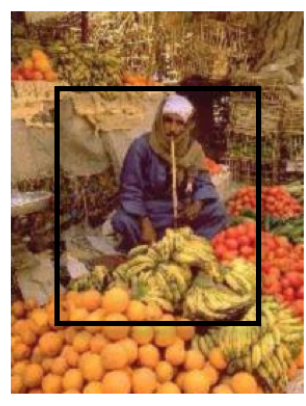

Figure 2c.

\section{Denial $\Rightarrow$ Polarization $\Rightarrow$ Minimization $\Rightarrow$ Acceptance $\Rightarrow$ Adaptation}

Figure 2. Intercultural orientations and developmental continuum.

The polarization orientation is driven by the assumption "Everybody should be like me/my group" and means viewing difference in terms of a stark "us" and "them." Evaluative prompts about student thinking (left side of Table 1) may be more likely for this orientation. Developing along the continuum towards ethno-relative perspectives leads to a minimizing of difference, focusing on similarities, commonality, and presumed universals (e.g., biological similarities - we all have human brains so we all learn math essentially the same way; and values - we all know the difference between right and wrong and naturally will seek right). This is the "minimization" orientation. A person with this orientation will be blind to recognition and appreciation of subtleties in difference (e.g., Figure 2b, a representation of, literally, the view of a colorblind person). The minimization orientation tends to take the form of ignoring 


\section{Developing a Model of Pedagogical Content Knowledge for Secondary and Post- \\ Secondary Mathematics Instruction \\ Shandy Hauk, Allison Toney, Billy Jackson, Reshmi Nair and Jenq-Jong Tsay}

fine detail in how people might have differing ways of thinking. For example, efforts at eliciting (right side of Table 1) may take the form of questions that allow listening for particular ways of thinking. This is in contrast to a teacher attempting to set a classroom norm for dialogue in which teacher and students listen to each other.

Transition from a minimization orientation to an "acceptance" orientation involves attention to contextual nuance and a growing awareness of self and others in two ways: (1) as potentially having a preferred cultural alignment, and (2) as belonging to cultures (plural) that may differ in both obvious and subtle ways. While aware of difference and willing to interact (e.g., engage in dialogue and carefully listen to others), how to respond and what to respond in the moment of interaction is still elusive. From the acceptance orientation, classroom discourse may include eliciting prompts, but sustained cycles of interactions can be challenging to maintain in the immediacy of dynamic classroom conversation and shifting contexts.

The transition to "adaptation" involves developing frameworks for perception, and responsive skills that value dialogic interaction and attend to a spectrum of detail in an interaction (e.g., the detailed and contextualized view in Figure 2c). Adaptation is an orientation where one is aware of multiple relative perspectives, and may - without violating one's authentic self - adjust communication and behavior in contextually appropriate ways.

An additional theorized developmental stage, integration, has yet to be thoroughly documented by researchers (in terms of Figure 2, it might be analogous to the image in Figure 2c suddenly becoming a motion picture with sound). Integration is a form of adaptation, it is theorized, that may be reached by someone like an especially effective hostage negotiator or particularly adept diplomat (Bennett \& Bennett, 2004). There is an instrument for measuring general intercultural orientation along the continuum up to adaptation (Hammer, 2009; see idiinventory.com).

The central idea here is that such orientations are learned, developmentally, and are part of teacher (and student) orientation towards each other and towards mathematics teaching and learning (Bennett, 1993, 2004; DeJaeghere \& Cao, 2009). Bishop (1991) conceptualizes mathematical acculturation as a "re-creative act" (p. 166) - where all members recreate, redefine, and "re-live" the symbols, concepts, and values of the mathematical culture. Engaging students in respectful dialogue for this purpose includes attending to the culture(s) all bring into the classroom (Prediger, 2001). Teacher skill in paying attention to these cultures depends on intercultural orientation.

\section{Extended Model of Pedagogical Content Knowledge}

Pragmatically, having viable models for the system that is "classroom teaching and learning" helps teachers, teacher educators, and other instructional professional developers and researchers improve the process of teacher learning in directions that support student learning. Years ago, in the classroom visits and interviews we conducted with mathematics teachers, we noticed the significance of mathematical syntax and the mathematical register. We found the existing models did not provide a variable for what was important in describing and predicting for the system we were investigating.

While Hill, Ball, and colleagues (2008) took a classical measure theory approach to identifying and measuring K-8 teacher knowledge, we continue to investigate a non-linear alternative (i.e., instead of the traditional linear methods such as hierarchical linear modeling - more on this below). In particular, our current approach adds a fourth sector to the MKT model of PCK, Knowledge of Discourse. Like Speer and King (2009), our observing, interviewing, and developing of assessments about secondary and post- 
secondary mathematics teaching has required re-thinking the content and relationships in the MKT model.

Depaepe and colleagues' (2013) review of mathematics pedagogical content knowledge across the English-speaking world noted that some researchers take a perspective on PCK as stable knowledge structures while others focus on the dynamics of understanding by teachers. We blend the two in a model that is anchored in fairly stable knowledge structures (the three in the MKT model plus Knowledge of Discourse) and attends to the connections among them. Here we focus on relational understandings and the thinking that connects Knowledge of Discourse with the three original PCK knowledge components. As indicated in Figure 3, we call the connections from Knowledge of Discourse to Knowledge of Curriculum curricular thinking, to Knowledge of Content and Students (KCS) anticipatory thinking, and to Knowledge of Content and Teaching (KCT) implementation thinking. These differ from stable knowledge collections in that each is a kind of thinking linked to proceptual understanding (Gray \& Tall, 1994), thinking that integrates relational components along with instrumental ingredients (Skemp, 1976). We seek to identify, prompt for, and assess the connected and overlapping relational aspects, especially in how the three types of thinking (curricular content, anticipatory, implementation) interact with knowledge of curriculum, KCS and KCT to be generated by and generative of Knowledge of Discourse. We use the phrases, Knowledge of Discourse, Curricular Thinking, Anticipatory Thinking, and Implementation Thinking in the following ways:

Knowledge of Discourse is knowledge about the culturally embedded nature of (big D) discourse, including inquiry and forms of communication in mathematics (both in and out of educational settings). It includes what a teacher knows of normative and non-standard mathematical vocabularies, representations, and artifacts.

Curricular Thinking is ways of thinking about (strategies, approaches to) mathematical topics, procedures, and concepts as well as the relationships among them. This includes the vertical knowledge of pre-requisite topics and potential future topics, as well as the relationships among them, along with conventions for reading, writing, and speaking them, found in curricula. In its most robust form, this part of PCK contributes to what Ma (1999) called "profound understanding of mathematics" (p. 120). In combination, Knowledge of Curriculum, curricular thinking, and Knowledge of Discourse are the home of Simon's (2006) "key developmental understandings."

Anticipatory Thinking is ways of thinking about (strategies, approaches to) how learners may engage with content, processes, and concepts. It includes awareness of and responsiveness to student thinking. Part of anticipatory development involves what Piaget called "decentering" - building skill in shifting from an ego-centric to an ego-relative view for seeing or communicating about an idea or way of thinking from the perspective of another (e.g., eliciting, noticing, and responding to student thinking; Carlson et al., 2007). Teachers with complex anticipatory thinking manage the tensions among their own instrumental and relational understandings of mathematics and its learning and those of their students. Such perspective-shifting is deeply connected to discourse through the awareness of "other" as different from "self." We see this as intimately connected to intercultural orientation.

Implementation Thinking is ways of thinking about (strategies, approaches to) how to enact teaching intentions in the classroom. Moreover, for us, it includes how to adapt teaching according to mathematical content and socio-cultural context and act on decisions shaped by intercultural orientation. This draws on knowledge of discourse(s) - including that of advanced mathematics - and on knowledge of mathematics-specific instructional practices. While the status quo is often an intention to enculturate in 


\section{Developing a Model of Pedagogical Content Knowledge for Secondary and Post- \\ Secondary Mathematics Instruction \\ Shandy Hauk, Allison Toney, Billy Jackson, Reshmi Nair and Jenq-Jong Tsay}

the sense of Kirshner's (2002) "teaching as enculturation" (i.e., to identify a reference culture and then target instruction for students to acquire particular dispositions), we have seen implementation thinking move beyond this, driven by greater Knowledge of Discourse.

Implicit in the MKT model is that one can witness and describe mathematical knowledge for teaching with an associated metric. Ball and colleagues have developed some measures for the types of knowledge that make up the MKT model, and have reported their struggles to isolate the types. That is, they have taken a piece-wise linear approach to modeling MKT as a proxy for determining teacher quality of instruction, with the idea that a good predictive model for teacher quality would look like an equation with three independent variables. For example, in the three parts of PCK in the MKT model, a linear approach says that if we can measure KCS, Knowledge of Curriculum, and KCT and add them up, it will capture PCK in a way that can be predictive of the quality of instruction.

Modeling this in an equation-like structure would look like

Teacher Quality $=a S(x)+b C(x)+c T(x)$

where $S, C$, and $T$ are measures of KCS, Knowledge of Curriculum, and KCT for teacher $x$ (e.g., from student scores on national tests, classroom observation protocol scores, etc.) and the coefficients a, $b$, and $c$ might be numerical weights for relative contribution of each type of knowledge in characterizing "quality." According to this line of thinking, once $a, b$, and $c$ are given, and once values of $S, C$, and $T$ are determined for teacher $x$, an assertion can be made about the quality of teaching available in the classroom of teacher $x$. We do not challenge the basic modeling assumption. Rather, we suggest that a more complex model beyond the linear assumption may be a better fit for the dynamics in secondary and college settings.

Hill, et al. (2008) acknowledge the importance of teacher knowledge of standard and nonstandard mathematical representations and communication, but knowledge of discourse as we construe it does not appear explicitly in their model. The relative contribution to the quality of instruction of each term in a mathematical model of teacher quality may depend on teacher intercultural developmental orientation. For instance, a classroom environment where students frequently engage in mathematically rich conversation with each other may not be particularly challenging for someone with an Acceptance intercultural orientation to manage, but may be very challenging for someone in Polarization. In developing the non-linear model we need to work to determine to what extent the intercultural "signal strength" is essential in each term and coefficient, starting by considering the terms that include Knowledge of Discourse. We come back to the idea of mathematical modeling of the relationships in the conclusion section.

One way of visualizing our extension to the ideas in Figure 1, that highlights and focuses on the interplay among the components of the new and existing views, is as a tetrahedron whose base is defined by the existing MKT components with a new vertex of Knowledge of Discourse (see Figure 3 ). Our empirical research has focused on knowledge of discourse and the three "edges" connecting it to the components in Figure 3 (Hauk, Jackson, \& Noblet, 2010). 


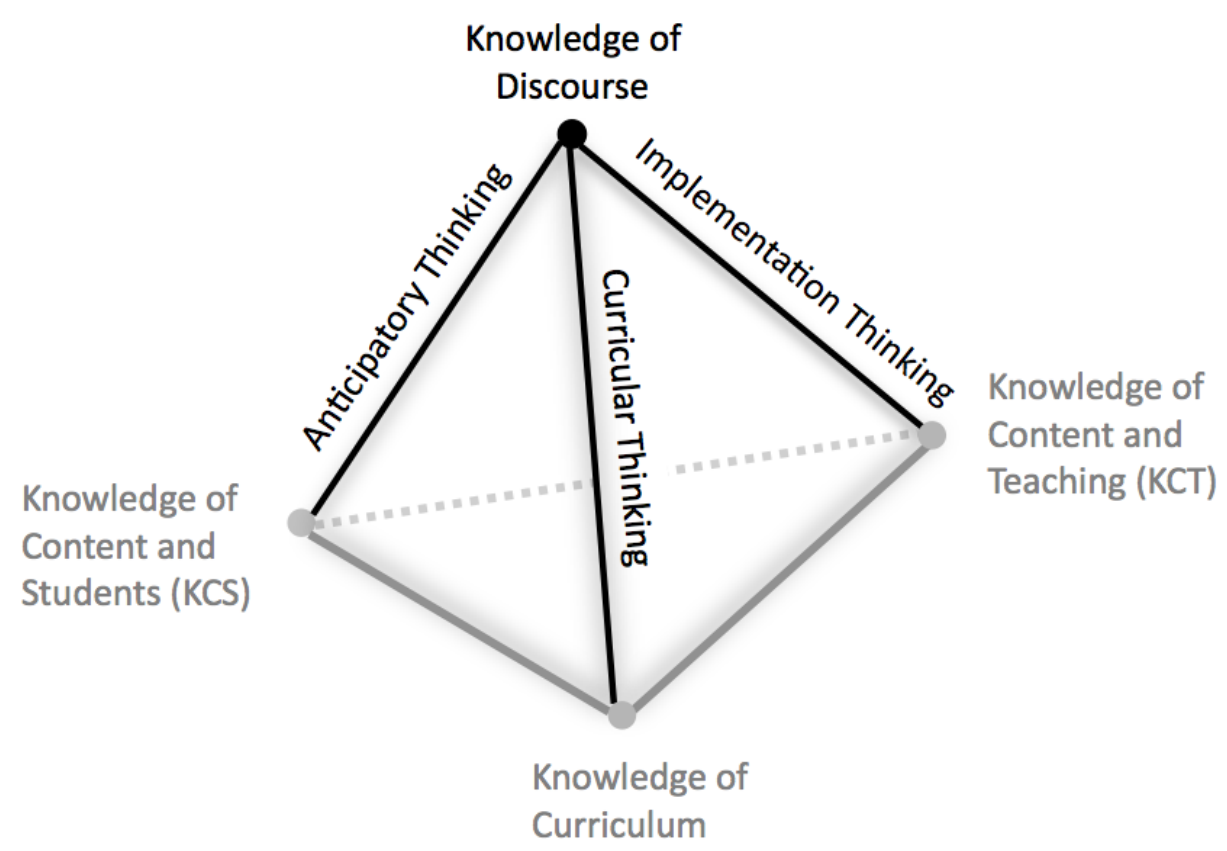

Figure 3. Tetrahedron - vertices, edges, and surfaces - as a way to visualize PCK components and relationships. Corners of the base are PCK dimensions from Figure 1.

\section{Vignettes and Discussion}

Over the last 10 years, the authors have been involved in a variety of ways in research and professional development with post-secondary faculty, in-service secondary mathematics teachers, and their students. In that work, mathematically trained stakeholders regularly ask us for examples and nonexamples of PCK in use. The first two vignettes included here are about Teacher Pat, a mathematics doctoral student at a large university whose teaching assistantship includes being the primary instructor for an algebra class. As instructor, Pat is responsible for establishing the syllabus, running the class (e.g., lectures, in-class activities, quizzes, tests), and assigning grades at the end of the term. The examples are based on real classroom transcripts from various research projects by colleagues and ourselves. Vignette 1 is Teacher Pat in the first year of teaching. Vignette 2 is Pat teaching the same course, in year 3 of teaching. Pat's professional learning in the intervening years included observing others' classes and participating in teaching seminars about noticing and responding to student thinking. As in many universities in the US, Pat's college algebra class is one of several, taught by different instructors, coordinated by an experienced faculty member. The coordinating professor with whom Pat worked, Dr. Gold, required graduate students to sit in on his own class meetings. A snapshot of Professor Gold's advanced algebra (group theory) classroom on the first day of the semester constitutes Vignette 3.

The vignettes are teacher-centered in various ways, to various degrees. The two vignettes from Pat allow noticing of the shifts in classroom practice and, arguably, increase in teacher quality from Pat's initial to fifth term of teaching. It is important to note that at the time of Vignette 2, Pat is still considered a novice teacher, though one who is moving away from a classroom practice aligned solely with the evaluative focus characterized on the left of Table 1. Vignette 3 with Professor Gold, who has 10 years of college teaching experience, reflects the fact that though often teacher-led, mathematics teaching also 


\section{Developing a Model of Pedagogical Content Knowledge for Secondary and Post- \\ Secondary Mathematics Instruction \\ Shandy Hauk, Allison Toney, Billy Jackson, Reshmi Nair and Jenq-Jong Tsay}

can be dialogic (Swan \& Swain, 2010; Wake \& Pampaka, 2008). By the time of Vignette 2, Teacher Pat has spent several years observing Dr. Gold, someone whose classroom practice includes the evaluating and eliciting practices represented in Table 1. Reading the additional vignette from Dr. Gold's class may give helpful information on the instruction that Pat observed. While much might be said about the presumptions in the set-up and problem contexts in the vignettes, the aim here is to highlight what we can understand about Pat's PCK in terms of knowledge of discourse, curricular thinking, anticipatory thinking, and implementation thinking.

\section{Vignette 1}

\section{COLLEGE ALGEBRA CLASSROOM*}

PAT (instructor) stands in front of whiteboard, 36 undergrads in 6 rows of 6 face him in small deskchairs. Problem on the board reads: At some time in the future John will be 38 years old. At that time he will be 3 times as old as Sally. Sally is now 7 years old. How old is John now? Shuffling of paper and scratching of pencils but no voices as students work.

Pat: Okay. Let's talk about this. What did you get? How is it that you thought about it?

Lee: I divided 38 by 3 . Then I subtracted 7 from 12 $2 / 3$ and got $52 / 3$. Then I subtracted that from 38 and got $321 / 3$. (Pause) John is $321 / 3$.

Pat: Right. (Pause) Why did you divide 38 by 3 ?

Lee: (Appearing puzzled by the question, Lee looks back at her work. She looks again at the original problem.) Because John is 3 times older.
Pat: Okay. (Looks around the room). Any questions? (Turns and erases the board).

Jackie (quietly to herself): Isn't the answer 21?

Pat: Hum? (Turns to face the room) No. If he was 21 he'd be three times as old as Sally is now.

Jackie: It says that he is 3 times as old as Sally, and Sally is 7 .

Pat: Well, the problem says John is 3 times as old when John is 38 , at some time in the future. (Pause) Do you understand?

Jackie: (shrugging): Okay.

Pat: Okay. Does anyone have any more questions? Okay. Now you try one, number 19 on page 33.

Problem 19. At some time in the past Luana was 24 years old. At that time she was 4 times as old as Rodney. Rodney is now 12 years old. When will Luana be 40 ?

*This and the content of Vignette 2 are adapted, with permission, from Thompson, Philip, Thompson, \& Boyd (1994).

Vignette 1. Teacher Pat's instruction in first year of teaching.

Knowledge of Discourse. In Vignette 1, Teacher Pat foregrounds the correct answer and a single path to that answer. That is, the primary discourse (little d) in the classroom is Pat's utterances to identify the correct procedure. This indicates the discourse (big D) is also centered with the teacher, as the kinds of explanations valued in the classroom are Pat's.

In Vignette 2, Pat asks students to "explain to us why you did what you did, what were you trying to find?" To participate, students have been asked explicitly to offer their own thinking to provide a convincing argument. Such eliciting questions by Pat are evidence of an intention to build a particular socio-mathematical norm for what is valued - both as connected strings of language and as mathematical communication. An aspect of the discourse, then, is that engaging in explanation is an expectation of all in the classroom. Pat evidences this again in the contribution of a table to organize information on the board as well as in the final question in the vignette. Pat's voice is first to propose the table. While still teacher-managed, the table could support the utterances in the room to shift towards conversation between teacher and students and among students. Knowing to explicitly request and use 


\section{Vignette 2}

\section{COLLEGE ALGEBRA CLASSROOM}

PAT stands in front of whiteboard, 36 students in 6 rows of 6 face him in small desk-chairs. John and Sally problem is on the board. Shuffling of paper, scratching of pencils, whispers as students work.

Pat: Let's talk about this problem a bit. How did you think about the information in it?

Sam: Well, you gotta start by dividing 38 by 3 . Then take away-

Pat: (Interrupting) Wait! Before you tell us about the calculations you did, explain to us why you did what you did. What were you trying to find?

Sam: Well, you know that John is 3 times as old, so you divide 38 by 3 to find out how old Sally is.

Pat: Do you all agree with Sam's thinking?

Several students say, "Yes"; others nod their heads.

Lia: That's not going tell you how old Sally is now. It'll tell you how old Sally is when John is 38 .

Pat: Is that what you had in mind, Sam?

Sam:Yes.

Pat: (To the class) What does the 38 stand for?

Lia: John's age in the future.

Pat: So 38 is not how old John is now. It's how old John will be in the future. (Pat starts a table on the board, as discussion continues, he adds to it)

\begin{tabular}{c|c|l} 
& Future & \\
\hline John & 38 &
\end{tabular}

The problem says that when John gets to be 38 he will be 3 times as old as Sally. Does that mean "3 times as old as Sally is now" or "3 times as old as Sally will be when John is 38 ?"

Several students respond, "When John is 38."

Jonah: Couldn't you just say John is 21? (Pause)

Couldn't you just multiply 3 times 7 ?

Pat: What will that give you?

Jonah: Twenty-one!

Pat: But what would 21 represent? What is it that's 21?

Jonah: That's how old John is now. Isn't that what we want to find?

Maura: No! (Pause) I mean, yes! That's what we want to find, but that's not right!

Pat: What is it that is not right, Maura? We do want to find out how old John is now, don't we?
Maura: Right. But see, he's not 3 times older than Sally now. He'll be 3 times older than Sally when he is 38 . You have to keep track of what's true now and what's so in the future.

(Pat adds a column and value to the table)

\begin{tabular}{c|c|c} 
& Future & Now \\
\hline John & 38 & \\
\hline Sally & & 7
\end{tabular}

Pat: Okay, so how are we going to use the information that John will be 3 times as old as Sally when he gets to be 38 ? (Pause) Who can explain?

Sam: You can divide 38 by 3 and get 12.66 ....

Pat: Remember to tell us what your numbers stand for. What does the $12.66 \ldots$ stand for?

Gina: That's how old Sally will be.

Pat: When?

Several: When John is 38 .

(Pat adds 12.66... to table)

\begin{tabular}{c|c|c} 
& Future & Now \\
\hline John & 38 & \\
\hline Sally & $12.66 \ldots$ & 7
\end{tabular}

Pat: (Looking around) Let's keep going. Nasir?

Nasir: Okay, you can say that Sally will be 12ish. So if you subtract 7 from that you get 5 . Then you take away 5 from 38 and get John is 33 . Done!

Pat: Wait a minute, too fast! Explain your reasoning.

Nasir: (Patiently) You know Sally will be 12 and something, and you know that she is 7 now. So that means that there are 5 years between now and then. Actually a little more than 5 years.

Pat: So 5 years is how much time there is between now and the time in the future when John is 38 ?

(Pat adds "5 years" and bracket above the table)

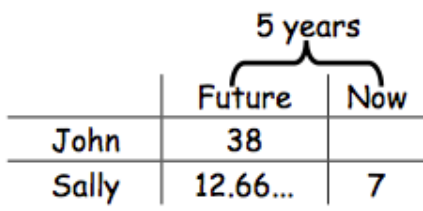

Nasir: Yes. So if you take 5 away from 38, that's how old John is now.

Pat: Did everyone follow that? (Pause) Who will recap the solution we've just been through?

Vignette 2. Teacher Pat's classroom instruction in third year of teaching

student-generated contributions to the table on the board could be a next step in Pat's development of the mathematical discourse. 


\section{Developing a Model of Pedagogical Content Knowledge for Secondary and Post- \\ Secondary Mathematics Instruction \\ Shandy Hauk, Allison Toney, Billy Jackson, Reshmi Nair and Jenq-Jong Tsay}

That is, Pat could have asked Gina and Nasir how to represent their contributions in the table or, opening the conversation more, asked students to take a few moments to consult with each other to explain their thinking then nominate representatives to step to the board and explain. Either move on Pat's part would require a change in intercultural orientation. Pat's focus in both vignettes is that students need to be more like an "us" to which Pat belongs: people who are adept at getting the right answer to a problem, articulate at justifying their reasoning, and direct in their validation of the reasoning of others. In Vignette 1, in getting the right answer into the air, Pat implements choice and product questions. In Vignette 2, Pat's eliciting questions are focused on getting mathematically valued justification and validation into the air in the room and correct values onto the board in a way valued by mathematics (in tabular form).

Curricular Thinking. There are subtle and distinct differences between the two vignettes with respect to Pat's content questioning. In Vignette 1, Pat's responses include immediate correct or incorrect feedback. Pat also mentions briefly the idea of a larger goal of understanding, while what constitutes such understanding is implicit. Unlike Vignette 1, in Vignette 2, Pat's questioning provides cognitive conflict about central concepts (particularly about interpreting temporal ordering) and scaffolds the use of key mathematical practices (visual organization of information, parsing arithmetical relationships, and to some extent, reasoning as a problem-solving approach). To resolve the challenges, students attend to the properties of time, context (e.g., age is usually precise only to the year, it is uncommon to say "I'm 32 and $1 / 3$ years old"), and also may notice their juxtaposition (the table). Richer curricular thinking, while still at the same intercultural level, on Pat's part might have led to a format for the table that placed "Future" to the far right and gave room for "Now" to its left in preparation for standard mathematical formats encountered later in the text. A potential connection to the next curricular step lurks in the background as Pat ends the segment by directing students to reflect on what they think. However, throughout, his curricular thinking is constrained by the values Pat enacts - of success defined by the class "covering the material" in short, right-answer-rich bursts rather than being defined by verification of rich conceptual understanding for all the students in the room.

Anticipatory Thinking. In Vignette 1 , Pat demonstrates anticipatory thinking (and $l \cdot R \cdot F$ evaluative approval) of a correct solution path expressed as procedural knowledge. Pat does not appear to anticipate the variation in student thinking in the room. Pat evaluates Jackie's statement rather than taking up the statement as an anticipatory opportunity about student confusion. That is, in Vignette 1 , Teacher Pat does not appear to anticipate common student struggles, while also probing about a (possible) struggle (deciding to divide by 3 ) in a way that is not especially productive. This leads to a question about the nature of anticipatory thinking and its relationship to what actually happens in the classroom: How might anticipatory thinking be seen as subtly and grossly different from implementation thinking? As we see in Vignette 2, anticipation can be a resource for enhancing students' opportunities to make sense of mathematics. In Vignette 2, Pat asks questions that elicit student thinking. Also, Pat anticipates that students may possess some knowledge about managing the information in the problem, particularly the temporal ordering aspects, but may not recognize their interaction in the context of the particular proposition in question. Pat looks to elicit an intellectual need for accommodation by having students consider the potential mismatch of information through a representation (the table). In Vignette 2, anticipating and eliciting of student thinking are central and are leveraged by Pat for finding out more (and building KCS) by asking students to speak about their rationales as part of working through the problem. It takes time to build skill in planning for, and reflecting on, interactions with students. Even with attendance at seminars where the focus was attention to student thinking, in Vignette 2 Pat is still in the early stages of building Knowledge of Discourse to draw meaning from conversations with and among 
students. Such knowledge is needed for anticipatory thinking that organizes student meaning and mathematical ideas into Knowledge of Content and Students.

Implementation Thinking. Vignette 1 indicates Pat has a solution map in mind for steps of an example and Pat's implementation thinking includes putting Pat's idea of a correct solution path into the air in the room. While Teacher Pat's own subject matter knowledge may operate without loss of generality, that strategy may not be familiar to or understood by students. That is, Vignette 1 is pedagogy aimed at getting an answer through proceduralizing problem-solving (e.g., "What did you get?"). There is no student-to-student interaction and when Pat overhears Jackie's question, the response is to evaluate and correct. In Vignette 2, Pat elicits and connects student thinking to procedures and concepts. Pat's implementation opens the way for students to make sense of each other's ideas, although students have not yet taken over the responsibility of sense-making for others' ideas. As students present their thinking, Pat emphasizes reasoning rather than the product (e.g., "What does the $12.66 \ldots$ stand for?" and "Wait a minute, too fast! Explain your reasoning"). Pat also uses multiple modes of discourse, including a common mathematical visual referent on the board, student generated statements, unspoken recording in the table, and confirming questions in order to support the needs of various students. Pat asks the students to clarify their terminology and language so others can make sense of it and share their understanding (e.g., "What is it that is not right, Maura?"). The connection between what has been put on the board and what "solving the problem" means remains unspecified at the end of Vignette 2. Pat's implementation thinking in Vignette 1 focused on getting the right answer in the air whereas Pat's implementation approach in Vignette 2 seems to incorporate aiming for the next curricular step, attending to student thinking, and attention to making sense of and reasoning about the mathematics at hand. A next developmental step for $P$ at will be working to have his students generate and explain representations such as the table Pat draws in Vignette 2.

Vignette 3 is an excerpt from a longer vignette on the first day of class for Dr. Gold, teaching advanced algebra (group theory). A more extensive vignette is available as an online Appendix (Toney, Hauk, \& Hsu, 2013). In it is an example of the teacher giving ownership of the board to the students along with talk and questions informed by an intercultural orientation that is at least at the developmental level of minimization - presuming students will share the instructor's view that students have responsibility for sense-making about each other's utterances and about the mathematical ideas.

Gold structures the lesson so students talk together about the mathematics in small groups and then in whole-class discussion. This structure centers on students talking with each other and having their voices heard. For example, in whole-class conversation students raise their hands, Gold solicits ideas and then provides pauses and think time, and then asks for hands again. In small group interaction, Gold effectively anticipates student communication struggles and supports student-centered development of concepts, enacting his initial message "Be prepared to tell me why your picture has the look that it does" with eliciting questions to groups collectively and to students individually as responsible agents in sensemaking and explanation (e.g., his approach to Group 4 in Vignette 3, and other interactions in the full vignette). 


\section{Developing a Model of Pedagogical Content Knowledge for Secondary and Post- \\ Secondary Mathematics Instruction \\ Shandy Hauk, Allison Toney, Billy Jackson, Reshmi Nair and Jenq-Jong Tsay}

\section{Vignette 3 - Snapshot of a Classroom}

\section{ADVANCED ALGEBRA CLASSROOM}

DR. GOLD sits on the edge of a table in front of a whiteboard. Twenty students are seated among 36 small desk-chairs arranged in 6 rows of 6 , all facing the front of the room. It is the first day of class.

Gold (putting the course syllabus aside): All right. Well, I think we should do some math. How many people are there here? Looks like about (pointing at students and whispering numbers as he looks around the room) 20 people. This is great. Let's split up into 5 groups. And I will tell you how: I will ask you to count up to 5 and then go back to 1 . And you will remember your number. And you'll go to one of these big surfaces (gestures to boards).

[Dr. Gold establishes groups and asks students to move to board areas. Groups have 5 minutes to introduce themselves and write names on the board. Gold walks to each group, handing out markers to each student, then stands in the center of the room. After 5 minutes, Gold introduces a task verbally.]

Gold: Okay, my friends, it is now time to talk about triangles. You all know what a triangle is, right? Three sides, three angles (students smile and nod). Imagine holding a triangle in your hand so you can turn it all around and flip it over and over (gestures rotating and turning). Draw me a picture of a triangle, and think about all the possible ways you can turn that triangle around and flip it over. Draw something that represents all those ways. Be prepared to tell me why your picture has the look that it does. Come get me when you feel like you've got a good picture.

[Students work in their groups on the task. He roams the room, stopping at each group to observe and converse - example in full vignette. As each group finishes the task he offers a handout with two new tasks (1) Given a triangle, describe the set of rotations that leave the triangle fixed. (2) Now add the reflections to the triangle to this set. Describe the set.]

Gold (approaching Group 4 after 15 minutes of work): This is a nice picture. Can you all explain it to me? (Students nod) So, I could ask any of you to tell me about it, and you'd all be pumped? ( 3 students nod) Okay, great! (Looking at 4th student) Why don't you tell me the story of this picture?
Daylen: We decided "leave the triangle fixed" meant whatever we do to it, it has to look like the original triangle. And the only way for that to happen is to have an equilateral triangle (others nod). So, we started messing with it and labeled the points $A, B$, and $C$ so we could stay organized. Then we could say this rotation (Puts hand by the board and rotates it to indicate rotating the triangle clockwise by one- third) makes it $B C A$, and this rotation (puts hand by the board and rotates clockwise by two-thirds) makes it $C A B$. And then we reflected three times using each point and the middle of the opposite side.

Gold: Okay. Do you all agree with that explanation?

John (laughing): Is that the right answer?

Gold: I thought it was a good answer. I think it's time to go whole class.

(Gold walks to center of the room, students turn to see him, some are talking)

Gold: Okay, my friends, it is that special time of the class when we talk together as one group. Who would like to tell me...I know it's hard to stop talking sometimes. We're now at whole-class conversation (Gold stops talking and waits until it is quiet). I want to debrief. First, look around at what people drew. And you can privately think about whether you think people are crazy or whether you agree with the pictures they drew. (Gold pauses for 1 minute) Do you see all these interesting shapes? There's some really out-there ones. I mean that in a good way. I'll take a few hands, if anyone wants to tell me about a picture they see. (Several people begin talking.) Wait, wait, wait, l'll call on you in a second. But I want to see some hands from some people who would like to comment on this. Okay, great. I see two hands. Anyone else have an opinion? l'd like to see a few more. Think about it for 10 seconds. (Waits 10 seconds.) Okay, can I see some hands from anyone who has some ideas about these diagrams? Okay, I see four hands. Let's go around...

[See the full vignette for examples of teacher-group interaction and whole-class discussion details along with Gold's explicit statements about classroom socio-mathematical norms.]

Vignette 3. Dr. Gold's classroom instruction in tenth year of teaching. 


\section{Conclusion}

Teaching requires complex management of instructional resources, including the teacher's own subject matter and pedagogical content knowledge. How communication is initiated, normed, and revised in the classroom is shaped by intercultural awareness. We have attempted to include the shaping of classroom mathematics communication in an extended theory of pedagogical content knowledge as Knowledge of Discourse. Success in teaching advanced mathematics is not just about what is said, but also how it is said, by whom, and with what warrant. Effective teaching extends beyond precise and accurate transmission of facts or uptake by students of information and includes taking into account the background and experiences (mathematical and otherwise) of the people in the room. Thus, teachers must make decisions informed by that knowledge to shape opportunities for learning (Schoenfeld, 2013).

An area of ongoing work for us are the relationships among intercultural orientation, self-aware use of the mathematical register in teacher talk, and what orientation(s) towards intercultural difference, mathematics as a discipline, and mathematics teaching as a profession may be necessary, if not sufficient, for rich discourse development for mathematics teaching. In particular, we continue to explore the extant literature on the concept of "decentering" as one potential instantiation of the developmental intercultural continuum that might be seen at work in classrooms. Mentioned by Piaget (1955), decentering refers to making a concerted effort to be aware from another person's perspective, particularly when that other perspective is different from one's own. This is, of course, related to the ancient advice to not judge fellow beings until having walked their footsteps. Decentering is a particular approach to awareness of "other" entailed by the definition of radical constructivism (e.g., see von Glasersfeld, 1995, chapter 6 on constructing agents; see also Carlson, et al., 2007 on decentering in professional learning; and Steffe and Thompson, 2000, on intersubjectivity).

On a separate note, the visualization of the extended theory as the vertices, edges, and faces of a tetrahedron may offer a way of articulating how intercultural orientation, as part of discourse, may be seen (tacitly or overtly) in looking at PCK. Suppose each of the four faces in Figure 3 represents a multidimensional interaction. As an example, consider the obscured face at the back of Figure 3; if we label the "edge" between KCT and KCS (perhaps call it balancing intended and achieved concepts) then - if we can go this far without breaking the usefulness of the visual model - how might instructional activity near the lower edge of the face be different from instructional activity on the same face, but closer to the Knowledge of Discourse vertex? Perhaps the difference is the nature of decentering. Or, perhaps it is a more complex intercultural constellation of which decentering is part. Conversely, in comparing Vignettes 1 and 2, where might we point or trace paths on the tetrahedron to indicate that Pat had built some skill in generating and sustaining conceptually focused discourse during instruction?

The main analysis of vignettes included here was for Pat, a relatively novice college instructor teaching traditional undergraduates. We have also talked amongst ourselves and colleagues about the situation where a professor is instructor to a room full of in-service secondary mathematics teachers. In our research with a set of mathematics $\mathrm{PhD}$ faculty, the distribution of intercultural orientations across the developmental continuum has been centered in minimization with small variance. At the same time, though distributed more widely across the developmental continuum, the in-service teachers in our work (over 100) have intercultural orientations centered at polarization (Hauk, Yestness, \& Novak, 2011; faculty and teachers completed measures of intercultural orientation).

We have seen many in-service teachers coming from a noticing of difference (polarization) orientation who are ready to think about and pay attention to how others' approaches to learning might differ from their own. Meanwhile, their professors (leading graduate classes and professional 


\section{Developing a Model of Pedagogical Content Knowledge for Secondary and Post- \\ Secondary Mathematics Instruction \\ Shandy Hauk, Allison Toney, Billy Jackson, Reshmi Nair and Jenq-Jong Tsay}

development workshops) have tended to minimize difference. So, when teacher-learners spoke in class about their mathematical understandings and how they differed, professors suggested it was most important to see how the approaches were essentially the same. That is, a challenge for the professors was how to notice nuances in the differences across teacher-learners' ways of thinking and use that information in their own anticipatory and implementation thinking. Faculty whose instruction of undergraduates in advanced mathematics courses looked like Pat in Vignette 2, were more like Pat in Vignette 1 when working with in-service teachers. The diversity of background and content knowledge is much greater in the teacher-learner population than is typical among undergraduate math majors. It may be that the intercultural pressures on Knowledge of Discourse can be so large as to impede flow along the anticipatory and implementation thinking edges of the tetrahedron.

A complementary area for research that might illuminate the relationships is looking at the classroom interactions for polarization-centered in-service secondary teachers. A polarization orientation means identifying difference is a ready skill, but identifying and building on commonality is a challenge. We continue to explore what it means to have rich Knowledge of Discourse and how it and orientation towards cultural difference can support teaching that balances and engages with myriad cultures in-themoment to scaffold effective mathematical communication among all in the room.

A related area of interest for us is experienced teachers' epistemological perspectives on mathematics and the teaching and learning of mathematics (Chamberlin et al., in press). Many see mathematics as a culture (Prediger, 2001). A teacher's perspective about mathematics is vital in determining the culture of their classroom and in teaching specific math topics. A teacher with a traditional view perceives mathematics as objective and focuses on transmitting the mathematical facts to students who are receivers of knowledge. In contrast, a reform-oriented perspective aligns with a social constructivist view. Mathematics is seen as dependent upon human activity and students are encouraged to actively construct an understanding by reasoning on their own and with others. In addition, the perspectives of a teacher inform decisions on the selection of teaching materials for specific topics, ways to assess students, and how to build upon ideas. Thus, it guides teachers' curricular, anticipatory, and implementation thinking (and students' too, when they become co-teachers).

In this article, we did not provide narrow definitions for the new constructs for the model. Instead, we described the terms as thoroughly and variedly as we could to help, but not to confine, readers to build up potential uses for further research. A pragmatic purpose of this PCK model is for identifying how knowledge of content and discourse is inextricably linked with knowledge of content and students, of content and teaching, and of curriculum. Not explicit in the new model are important variables that inform and condition the development of the ways of thinking in our model.

Essentially, we have proposed two changes to the current model, (1) the addition of Knowledge of Discourse as a variable to be described/measured and (2) a non-linear relationship. That is, we include the interdependence of Knowledge of Discourse with KCS, KCT, and Knowledge of Curriculum through the connectors Anticipatory Thinking, Implementation Thinking, and Curricular Thinking, respectively. Inevitably, there are both similarities and differences between teachers' own mathematical acculturations, their own everyday cultures, prior mathematical enculturation of students, everyday culture of students, intended mathematical enculturation of the curriculum or school, and interim classroom cultures that combine all of these. How teachers and learners approach navigating those different discourses, establishing classroom mathematical discourse(s), and the tools they have to do this is informed by their intercultural orientation. 
One way to represent that dependence on intercultural orientation in a non-linear mathematical model in an equation-like setting would be to introduce a new parameter, $i$, for intercultural development. We assume that coefficients in a non-linear model will not be uniform, but rather, the coefficients themselves might be better modeled as depending on intercultural orientation. To be mathematically specific, we noted earlier the linear assumption might be modeled:

Teacher Quality $=a S(x)+b C(x)+c T(x)$,

where $S, C$, and $T$ are measures of KCS, Knowledge of Curriculum, and KCT for teacher $x$. In a non-linear approach, one might consider an equation similar to the one below,

$$
\text { Teacher Quality }=a S(x)+b C(x)+c T(x)+w(i) D(x)+p(i) D(S(x))+q(i) D(C(x))+r(i) D(T(x)) \text {. }
$$

It is in the interplay represented by the non-linear terms like $D(S(x))$, representing interaction between Knowledge of Discourse and Knowledge of Content and Students, that we explore the aspects of thinking (in this case, Anticipatory Thinking). For example, if the original three-term linear equation were sufficient, then research would suggest that the non-linear equation's coefficients $p, q$, $r$, and $w$ would be virtually zero. Hill, Ball, and Schilling's (2008) report, however, suggests that at least the terms $p(i) D(S(x))$ and $r(i) D(T(x))$ will play a role. How to document and measure these terms in the real classroom drives our next steps as researchers and as assessment developers.

Finally, we share two suggestions for our ongoing work that have arisen out of recent lively discussion. One was the recommendation that development of the theory presented here pursue the distinction between "ways of thinking" and "ways of understanding" (see, e.g., Harel, 2008). Doing so might open up the model to learners-as-teachers. The current model only addresses the perspective of an individual teacher and not a dialogic cooperative of learner-teachers. Also emerging from discussion was the suggestion that we consider a further extension of the visual model of PCK to all of MKT with the addition of another tetrahedron for the subject matter knowledge components (left side of Figure 1), linked to the PCK model through the Knowledge of Discourse vertex. It is still an open question whether this linking could be useful in thinking about, describing, and developing the knowledge used for teaching advanced mathematics.

\section{Acknowledgement}

This material is based upon work supported by the National Science Foundation (NSF) under Grant No. DUE0832026 and the Institute of Education Sciences, U.S. Department of Education through Grant R305A100454. Any opinions, findings and conclusions or recommendations expressed are those of the authors and do not necessarily reflect the views of the NSF, the Institute, or the U.S. Department of Education.

\section{References}

Alibali, M. W., Wolfgram, W., Young, A. G., Church, R. B., Johnson, C. V., Jacobs, S. A., \& Nathan, M. J. (2012). Linking mathematical ideas multimodally enhances learning. Paper presentation to the American Educational Research Association annual meeting (Vancouver, BC).

Anderson, C. W., \& Smith, E. L. (1987). Teaching science. In V. Richarson-Koehler (Ed.) Educators' handbook $-A$ research perspective (pp. 84-111). New York: Longman.

Arcavi, A., Kessel, K., Meira, L. \& Smith, J. P. (1998). Teaching mathematical problem solving: An analysis of an emergent classroom community. In J. Kaput, A. H. Schoenfeld, \& E. Dubinsky 


\section{Developing a Model of Pedagogical Content Knowledge for Secondary and Post- \\ Secondary Mathematics Instruction \\ Shandy Hauk, Allison Toney, Billy Jackson, Reshmi Nair and Jenq-Jong Tsay}

(Eds.), Research in collegiate mathematics education III (pp. 1-70). Providence, RI: American Mathematical Society.

Bair, S. L., \& Mooney, E. S. (2013). Mario, monkey man, fish, and bam-bam: Creative terminology in today's classrooms. The Mathematics Teacher, 106, 408-409.

Ball, D. L., Thames, M. H., \& Phelps, G. (2008). Content knowledge for teaching: What makes it special? Journal of Teacher Education, 59, 389-407.

Barwell, R. (2005). Ambiguity in the mathematics classroom. Language and Education, 19(2), 117-125.

Bennett, M. J. (2004). Becoming interculturally competent. In J. Wurzel (Ed.), Towards multiculturalism: A reader in multicultural education (2nd ed., pp. 62-77). Newton, MA: Intercultural Resource Corporation.

Bennett, M. J. (1993). Towards ethnorelativism: A developmental model of intercultural sensitivity. In R. M. Paige (Ed.), Education for the intercultural experience $\left(2^{\text {nd }}\right.$ ed., pp. 21-71) Yarmouth ME: Intercultural Press.

Bennett, J. M. \& Bennett, M. J. (2004). Developing intercultural sensitivity: An integrative approach to global and domestic diversity. In D. Landis, J. M. Bennett, \& M. J. Bennett (Eds.), Handbook of intercultural training (pp. 147-165). Thousand Oaks, CA: Sage.

Bishop, A. J. (1991). Mathematical enculturation: A cultural perspective on mathematics education. Kluwer: Norwell, MA.

Carlson, M. P., Moore, K., Bowling, S., \& Ortiz, A. (2007). The role of the facilitator in promoting meaningful discourse among professional learning communities of secondary mathematics and science teachers. In T. Lamberg \& L. R. Wiest (Eds.), Proceedings of the 29th annual meeting of the North American chapter of the International Group for the Psychology of Mathematics Education (pp. 841-848). University of Nevada, Reno.

Chamberlin, M. T., Troudt, M. L., Nair, R., \& Breitstein, A. (in press). The perspectives of teacher leaders on mathematics, learning, and teaching: Supporting reform-oriented instruction. Journal of Mathematics Education Leadership.

DeFranco, T. C., (1996). A perspective on mathematical problem solving based on the performances of Ph.D. mathematicians. In Kaput, J., A. Schoenfeld, \& E. Dubinsky (Eds.), Research in collegiate mathematics education. II (pp. 195-213). Providence, RI: American Mathematical Association.

DeJaeghere, J. G., \& Cao, Y. (2009). Developing U.S. teachers' intercultural competence: Does professional development matter? International Journal of Intercultural Relations, 33, 437-337.

Depaepe, F., Verschaffel, L., \& Kelchtermans, G. (2013). Pedagogical content knowledge: A systematic review of the way in which the concept has pervaded mathematics educational research. Teaching and Teacher Education, 34, 12-25.

Driscoll, M. P. (1994). Psychology of learning for instruction. MA: Needham Heights.

Gay, G. (2010). Culturally responsive teaching: Theory, research, and practice, 2nd edition. New York: Teachers College Press.

Gee, J. P. (1996). Social linguistics and literacies: Ideology in discourses (2nd Ed.). London: Taylor \& Francis.

Gee, J. P. (1999). An introduction to discourse analysis: Theory and method. London: Routledge.

Gitomer, D., Phelps, G., Weren, B. Howell, H., \& Croft, A. (in press). Evidence on the validity of content knowledge for teaching assessments. In T. Kane, K. Kerr, \& B. Pianta (Eds.), MET Research Volume.

Gray, E. M., \& Tall, D. O. (1994). Duality, ambiguity, and flexibility: A proceptual view of simple arithmetic. Journal for Research in Mathematics Education, 25, 116-140.

Greeno, J. (1998) The situativity of knowing, learning, and research, American Psychologist 53(1), 5-26.

Habermas, J. (1984). The theory of communicative action, Vol. I. Boston: Beacon.

Dialogic Pedagogy: An International Online Journal | http://dpj.pitt.edu

DOI: 10.5195/dpj.2014.40 | Vol. 2 (2014) 
Hammer, M. (2009). The Intercultural development inventory: An approach for assessing and building intercultural competence. In M. A. Moodian (Ed.), Contemporary leadership and intercultural competence (pp. 203-217). Thousand Oaks, CA: Sage.

Harel, G. (2008). What is mathematics? A pedagogical answer to a philosophical question. In B. Gold \& R. A. Simons (Eds). Proof and other dilemmas: Mathematics and philosophy (pp. 265-290). Washington, DC: Mathematical Association of America.

Hauk, S., Jackson, B., \& Noblet, K. (2010). No teacher left behind: Assessment of secondary mathematics teachers' pedagogical content knowledge. In S. Brown (Ed.), Proceedings for the 13th Conference on Research in Undergraduate Mathematics Education (electronic).

Hauk, S., Toney, A., Jackson, B., Nair, R., \& Tsay, J.-J. (2013). Illustrating a theory of pedagogical content knowledge for secondary and post-secondary mathematics instruction. In S. Brown (Ed.), Proceedings of the 16th Conference on Research in Undergraduate Mathematics Education (Denver, CO).

Hauk, S., Yestness, N., \& Novak, J. (2011). Transitioning from cultural diversity to intercultural competence in mathematics instruction. In S. Brown (Ed.), Proceedings for the 14th Conference on Research in Undergraduate Mathematics Education (electronic).

Hill, H. C., Ball, D. L., \& Schilling, S. G. (2008). Unpacking pedagogical content knowledge: Conceptualizing and measuring teachers' topic-specific knowledge of students. Journal for Research in Mathematics Education, 39, 372-400.

Hill, H. C., Blunk, M., Charalambous, C., Lewis, J., Phelps, G. C., Sleep, L., \& Ball, D. L. (2008). Mathematical knowledge for teaching and the mathematical quality of instruction: An exploratory study. Cognition and Instruction, 26, 430-511.

Hill, H., Sleep, L., Lewis, J. M., \& Ball, D. L. (2007). Assessing teachers' mathematical knowledge: What knowledge matters and what evidence counts. In K. F. Lester (Ed.), Second handbook of research on mathematics teaching and learning (pp. 111-155). Reston, VA: NCTM.

Hilpinen, R. (1970). Knowing that one knows and the classical definition of knowledge. Synthese, 21, 109-132.

Karplus, R., \& Thier, H D. (1967). A new look at elementary school science. Science curriculum improvement study, Chicago, Rand McNally.

Kirshner, D. (2002). Untangling teachers' diverse aspirations for student learning: A cross disciplinary strategy for relating psychological theory to pedagogical practice. Journal for Research in Mathematics Education, 33, 46-58.

Lantz, O. \& Kass, H. (1987). Chemistry teachers' functional paradigms. Science Education, 71, 117-134.

Ma, L. (1999). Knowing and teaching elementary mathematics: Teachers' understanding of fundamental mathematics in China and the United States. Mahwah, NJ: Erlbaum.

Magnusson, S. J., Krajcik, J. S., \& Borko, H. (1999). Nature, sources, and development of pedagogical content knowledge for science teaching. In J. Gess-Newsome and N. G. Lederman (Eds.), Pedagogical content knowledge and science education (pp. 95-132). Dordrecht, The Netherlands: Kluwer.

Magnusson, S. J., \& Palincsar, A. S. (1995) Learning environments as a site of science education reform. Theory into Practice, 34(1), 1-8.

Mehan, H. (1979). Learning lessons: Social organization in the classroom. Cambridge, MA: Harvard University Press.

Moschkovich, J. (2007). Examining mathematical discourse practices. For the Learning of Mathematics, 27(1), 24-30.

Nickerson, S. \& Bowers, J. (2008). Examining interaction patterns in college-level mathematics classes: A case study. In M. Carlson and C. Rasmussen (Eds.), Making the connection: Research and 


\section{Developing a Model of Pedagogical Content Knowledge for Secondary and Post- \\ Secondary Mathematics Instruction \\ Shandy Hauk, Allison Toney, Billy Jackson, Reshmi Nair and Jenq-Jong Tsay}

practice in undergraduate mathematics education (pp. 179-190). Washington, DC: Mathematical Association of America.

Park, S. \& Chen, Y-C. (2012). Mapping out the integration of the components of pedagogical content knowledge (PCK): Examples from high school biology classrooms. Journal of Research in Science Teaching, 49(7), 922-941.

Prediger, S. (2001). Mathematics learning is also intercultural learning. Intercultural Education, 12(2), 163-171.

Piaget, J. (1955). The language and thought of the child. New York: Meridian.

Roth, K. J., Anderson, C. W., \& Smith, E. L. (1987). Curriculum materials, teacher talk, and student learning: Case studies of fifth grade science teaching. Journal of Curriculum Studies, 19, 527548.

Ryve, A. (2011). Discourse research in mathematics education: A critical evaluation of 108 journal articles. Journal for Research in Mathematics Education, 42(2), 167-198.

Schoenfeld, A. H. (2013). Classroom observations in theory and practice. ZDM: The International Journal on Mathematics Education, 45(4), 607-621, doi 10.1007/s11858-012-0483-1

Shulman, L. (1986). Those who understand: Knowledge growth in teaching. Educational Researcher, 15(2), 4-14.

Silverman, J., \& Thompson, P. W. (2008). Toward a framework for the development of mathematical knowledge for teaching. Journal of Mathematics Teacher Education, 11, 499-511.

Simon, M. A. (2006). Key developmental understandings in mathematics: A direction for investigating and establishing learning goals. Mathematical Thinking and Learning, 8(4), 359-371.

Skemp, R. (1976). Relational and instrumental understanding. Mathematics Teaching, 77, 20-26.

Solano-Flores, G., \& Nelson-Barber, S. (2001). On the cultural validity of science assessments. Journal of Research in Science Teaching, 38(5), 553-573.

Speer, N. M., \& King, K. (2009). Examining mathematical knowledge for teaching in secondary and postsecondary contexts. In M. Zandieh (Ed.), Proceedings of the 12th conference on Research in Undergraduate Mathematics Education (Raleigh, NC).

Speer, N. M., King, K., \& Howell, H. (in press). Definitions of mathematical knowledge for teaching: Using these constructs in research on secondary and college mathematics teachers. Journal of Mathematics Teacher Education.

Steffe, L. P., \& Thompson, P. W. (2000). Interaction or intersubjectivity? A reply to Lerman. Journal for Research in Mathematics Education, 31(2), 191-209.

Stigler, J. \& Hiebert, J. (2004). Improving mathematics teaching. Educational Leadership, 61(5), 12-19.

Swan, M. \& Swain, J. (2010). The impact of a professional development programme on the practice and beliefs of numeracy teachers. Journal of Further and Higher Education, 34(2), 165-177.

Tall, D., \& Vinner, S. (1981). Concept image and concept definition in mathematics with particular reference to limits and continuity. Educational Studies in Mathematics, 12(2), 151-169.

Tamir, P. (1983). Inquiry and the science teacher. Science Education, (67), 657-672.

Temple, C., \& Doerr, H. M. (2012). Developing fluency in the mathematical register through conversation in a tenth-grade classroom. Educational Studies in Mathematics, 81(3), 1-20.

Thompson, A. G., Philipp, R. A., Thompson, P. W., \& Boyd, B. A. (1994). Calculational and conceptual orientations in teaching mathematics. In A. Coxford (Ed.), 1994 Yearbook of the NCTM (pp. 7992). Reston, VA: NCTM.

Toney, A., Hauk, S., \& Hsu, E. (2013). Appendix A: Professor Gold and the first day of abstract algebra. Available online at: http://www.bookwalk.org/hauk/jdp/PCK/AppendixA.pdf

Truxaw, M. P., \&Defranco, T. C. (2008). Mapping mathematics classroom discourse and its implications for models of teaching. Journal for Research in Mathematics Education, 39(5), 489-525. 
van Zee, E. \& Minstrell, J. (1997). Using questioning to guide student thinking. The Journal of the Learning Sciences, 6(2), 227-269.

von Glasersfeld, E. (1995). Radical constructivism: A way of knowing and learning. London: Falmer.

Wake, G., \& Pampaka, M. (2008). The central role of the teacher - even in student centred pedagogies. In Proceedings of the Joint Meeting of PME32 and PME-NA XXX (vol. 4, pp. 377-384) Morelia, Mexico: PME.

Weber, K. (2004). Traditional instruction in advanced mathematics courses: A case study of professors' lectures and proofs in an introductory real analysis course. Journal of Mathematical Behavior, 23(2), 115-133.

Wells, G. (1993). Reevaluating the IRF sequence: A proposal for the articulation of theories of activity and discourse for the analysis of teaching and learning in the classroom. Linguistics in Education, 5(1), 1-37.

Wood, T. (1994). Patterns of interaction and the culture of mathematics classrooms. In S. Lerman (Ed.), The culture of the mathematics classroom (pp. 149-168). Dordrecht, The Netherlands: Kluwer.

Yackel, E., Rasmussen, C., \& King, K. (2000). Social and sociomathematical norms in an advanced undergraduate mathematics course. Journal of Mathematical Behavior, 19(3), 275-287.

Zandieh, M. (2000). A theoretical framework for analyzing student understanding of the concept of derivative. In E. Dubinsky, A. Schoenfeld, \& J. Kaput (Eds.), Research in Collegiate Mathematics Education IV (Vol. 8, pp. 103-127). Providence, RI: American Mathematical Society.

\section{(c)) EY}

New articles in this journal are licensed under a Creative Commons Attribution 4.0 United States License.

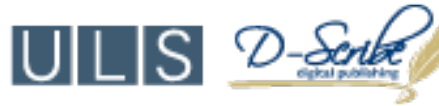

This journal is published by the University Library System, University of Pittsburgh as part of its D-Scribe Digital Publishing Program and is cosponsored by the University of Pittsburgh Press. 